\title{
Assessment of Cardiovascular Markers Inpatients with Type 2 Diabetes Who Smoke Cigarette
}

\author{
Ahmed M Ahmed \\ Department of Medical Laboratory Technology, Faculty of Applied Medical Sciences, Taibah University, Medina, \\ Saudi Arabia
}

\begin{abstract}
Background: diabetes and smoking were known serious factors for developing cardiovascular and other abnormalities threaten wellbeing.

Objective: to estimate the impact of smoking and diabetes on cardiovascular disease (CVD) markers.

Methods: 44 type 2 diabetes never smoke compared to 32 type 2 diabetes currently smoking and 30 healthy subjects, lipids, apolipoprotein, lp(a), CK-MB Troponin, MDA, and MPO were measured in participants.

Results: FPG, Lp(a) and MDA were higher in patients than controls ( $p>0.01)$. In addition, $\mathrm{Lp}(\mathrm{a})$ and MDA were higher in SDM than DM ( $>>0.05)$. Moreover, CVD markers were higher in smoker's patients with diabetes (SDM) who were overweight or hypercholesterolemia than others $(p>0.01)$. Furthermore, $L p(a)$ was increased gradually and correlate directly with diabetes in all three-period settings in the study $(\mathrm{p}>0.05)$.

Conclusion: smoking increased the risk of CVD in Sudanese type diabetes, the risk was increased with overweight, hypercholesterolemia and become serious in a long period of diabetes.
\end{abstract}

Keywords: Smoking, diabetes, CVD, and cardiovascular.

\section{Introduction}

Diabetes mellitus (DM) is a group of metabolic impairments characterized by chronic hyperglycemia due to low or complete absence of insulin, DM has increased recently worldwide because of the globalization of Western lifestyle. Diabetes mellitus disorders and complications were associated with the cardiovascular system and affected in both, microangiopathy and macroangiopathy vascular. microvascular complications are including coronary artery diseases, and microvascular complications including nephropathy in the kidney, retinopathy in the eye, and neuropathy ${ }^{1}$.

\section{Corresponding Author:}

\section{Dr. Ahmed M Ahmed;}

Associate Professor of Clinical Chemistry, Faculty of Applied Medical Sciences, Taibah University, Medina, Saudi Arabia
Cigarette smoking (CS) consider to be a major health threatening, it is predisposing factor for many diseases including cancer and atherosclerosis, it is leading significantly to CVD mortality, CS increases all stage of atherosclerosis since endothelial dysfunction until acute clinical events.CS is one of the most important risk factor increased risk of DM, smoking gives many toxins including reactive oxygen species which leading to oxidative stress and atherosclerosis ${ }^{2}$.

Cardiovascular diseases (CVD) are contributing a leading cause of death globally ${ }^{3}$. According to International Diabetes Federation, the number of diabetes is 347 million in 2008 and 366 million in 2011 and will be increasing to 552 million by 2030 in 10 countries $^{4}$.

DM in Sudan was estimated in 2001 as $3.4 \%{ }^{5}$ and increased to $7.7 \%$ in 2015 and expected $10.8 \%$ in $2035^{4}$. Sudan consider a developed country with difficult living 
Medico-legal Update, October-December 2021, Vol.21, No. $4 \quad 75$

and health conditions particularly in rural, so the number of research was scarce, but there is much research in adult and pediatric regarding diabetes, metabolic syndrome, and other risk factors associated with the risk of CVDs through many stages and complications in Sudan and others ${ }^{6-20}(5-19)$.In Sudan we look to many factors that help to decreases the risk of cardiovascular in populations, including the use of local herbals that well documented to decreasing risk factors such as $\operatorname{mint}^{21}$, and caffeine in coffee ${ }^{22}$, but the utilization of smoking is increased especially among young age ${ }^{23}$. Still, we need more researches to focus on the real number of diabetes, smoking, and other risk factors for CVD.

\section{Methods}

\section{Subjects:}

Forty-four patients with type 2 diabetes (26 male) who never smoke compared to 32 type 2 diabetes who smoke cigarettes (all of them were male) were recruited from Jabir Abu Aliz Diabetes Center (Khartoum, Sudan). The patients were compared to 30 healthy subjects (19 male) as a control group. The inclusion criteria for selecting patients were fasting blood glucose $\geq 7 \mathrm{mmol} / \mathrm{l}$. exclusion criteria were those with failure of kidney and liver, acute illness, anemia, and thyroid disease. The permission of this study was taken from the local research ethics committee which follows the standard criteria of the declaration of Helsinki. Written consent was signed by participants after the description of study aims.

\section{Anthropometricand Biochemical parameters:}

Body mass index (BMI) was measured as mentioned before ${ }^{24}$.

Fasting blood samples were collected from the participants in plain tubes and the serum separated close to the time of collection. Blood glucose and lipids were measures by enzymatic endpoint reaction with commercial kits as mentioned before ${ }^{16}$. Apo A1, apo B, and Lp(a) were measured based on the immunoturbidimetric method using automated analyzer Roche/Hitachi 902 fully-automated analyzer ${ }^{9,25}$. Urea and creatinine were measured according to enzymatic reaction ${ }^{26}$. Malondialdehyde (MDA) determined by the protocol as mentioned before ${ }^{27}$. The activity of Myeloperoxidase (MPO) was measured spectrophotometrically with the use of o-dianisidine (Sigma-Aldrich) and hydrogen peroxide as mentioned before $^{28}$.

\section{Statistical Analysis}

Done by using SPSS software version 19 (IBM Corporation, Armonk, NY, USA). Values were shown as mean $\pm \mathrm{SD}$. ANOVA and t-test were applied when appropriate for calculation of $\mathrm{p}$-value which considers significant if $\mathrm{p}<0.05$.

\section{Results}

Table 1 shows basic characteristics of study subjects, in which there were no significant differences between DM, SDM, and controls in all biochemical or anthropometric parameters except in FPG, Lp(a), and MDA levels, which were higher in patients both groups than in control $(p>0.01)$. In addition, $L p(a)$ and MDA were higher in SDM than DM ( $\mathrm{p}>0.05)$.

Table 2 shows a comparison of CVD markers among different characteristics in patients with diabetes and smokers, no significant difference between male and female, but CK and Troponin were higher in overweight and hypercholesterolemia subjects than others $(\mathrm{p}>0.01)$.

Table 3 shows a correlation between the duration of diabetes and markers in SDM, in which, Lp(a), CVD, and inflammatory markers were increased significantly in a long period ( $p>0.01)$. Lp(a) was increased gradually and correlate directly with diabetes in all three-period settings in the study $(\mathrm{p}>0.05)$. 
Table1: basic characteristics of participants

\begin{tabular}{|c|c|c|c|c|}
\hline & DM & SDM & Controls & $P$ value \\
\hline No. & 44 & 32 & 30 & - \\
\hline Age & $30.9 \pm 14.3$ & $42.1 \pm 19.7$ & $37.9 \pm 16.5$ & 0.06 \\
\hline Gender (male, female) & 26,18 & 32,0 & 19,11 & - \\
\hline BMI (kg/m2) & $23.5 \pm 3.9$ & $24.4 \pm 4.8$ & $22.1 \pm 2.1$ & 0.8 \\
\hline $\mathrm{FPG}(\mathrm{mmol} / \mathrm{l})$ & $8.2 \pm 1.2$ & $8.3 \pm 1.9$ & $5.2 \pm 0.5$ & $0.001 * *$ \\
\hline $\mathrm{TC}(\mathrm{mmol} / \mathrm{l})$ & $4.2 \pm 1.6$ & $4.5 \pm 1.8$ & $4.0 \pm 1.1$ & 0.39 \\
\hline $\mathrm{TG}(\mathrm{mmol} / \mathrm{l})$ & $1.51 \pm 0.4$ & $1.6 \pm 0.9$ & $1.48 \pm 0.3$ & 0.74 \\
\hline $\mathrm{LDL}(\mathrm{mmol} / \mathrm{l})$ & $3.3 \pm 1.1$ & $3.6 \pm 1.2$ & $3.1 \pm 0.9$ & 0.18 \\
\hline $\mathrm{HDL}(\mathrm{mmol} / \mathrm{l})$ & $1.28 \pm 0.7$ & $1.25 \pm 0.4$ & $1.41 \pm 0.7$ & 0.53 \\
\hline Apolipoprotein A1 (g/L) & $1.49 \pm 0.8$ & $1.45 \pm 0.8$ & $1.57 \pm 0.9$ & 0.84 \\
\hline Apolipoprotein B (g/L) & $10.2 \pm 4.9$ & $10.8 \pm 5.1$ & $9.1 \pm 2.9$ & 0.33 \\
\hline $\mathrm{Lp}(\mathrm{a}) \mathrm{mg} / \mathrm{dl}$ & $33.2 \pm 9.2$ & $38.7 \pm 12.1 *$ & $18.9 \pm 4.9$ & $0.001 * *$ \\
\hline $\mathrm{CK}-\mathrm{mb}(\mathrm{ng} / \mathrm{ml})$ & $2.2 \pm 0.9$ & $2.4 \pm 1.1$ & $1.9 \pm 0.7$ & 0.11 \\
\hline Troponin (ng/ml) & $0.019 \pm 0.03$ & $0.022 \pm 0.03$ & $0.008 \pm 0.01$ & 0.09 \\
\hline MDA (mg/dl) & $0.9 \pm 0.1$ & $1.0 \pm 0.1 *$ & $0.5 \pm 0.1$ & $0.001 * *$ \\
\hline MPO (ng/ml) & $32.1 \pm 12.8$ & $32.7 \pm 11.2$ & $26.5 \pm 7.8$ & 0.06 \\
\hline Urea (mg/dl) & $20 \pm 5.2$ & $22 \pm 8.1$ & $17 \pm 2.2$ & \\
\hline Creatinine (mg/dl) & $0.8 \pm 0.1$ & $0.9 \pm 0.2$ & $0.7 \pm 0.2$ & \\
\hline Smokers & 9 & 17 & 0 & - \\
\hline Non-smokers & 13 & 23 & 26 & - \\
\hline
\end{tabular}

DM: diabetes mellitus patients. SDM: smokers with diabetes mellitus patients.Data set as mean \pm SD. *significant $p>0.05 .{ }^{* *}$ significant $p>0.01$. 
Table 2: CVDs markers in smoker diabetic patients

\begin{tabular}{|c|c|c|}
\hline & CK-mb & Troponin \\
\hline \multicolumn{3}{|l|}{ Gender } \\
\hline Males $(n=40)$ & $2.4 \pm 0.8$ & $0.023 \pm 0.01$ \\
\hline Females $(n=22)$ & $2.2 \pm 0.4$ & $0.020 \pm 0.01$ \\
\hline \multicolumn{3}{|l|}{ BMI } \\
\hline Normal (20) & $3.1 \pm 0.4^{* *}$ & $0.021 \pm 0.01$ \\
\hline Overweight (42) & $2.5 \pm 0.3$ & $0.029 \pm 0.01 * *$ \\
\hline \multicolumn{3}{|l|}{ Total cholesterol } \\
\hline Normal (48) & $2.6 \pm 0.9$ & $0.021 \pm 0.01$ \\
\hline High level (14) & $3.9 \pm 0.9 * *$ & $0.037 \pm 0.01^{* *}$ \\
\hline
\end{tabular}

Data set as mean \pm SD. ${ }^{* *}$ significant $\mathrm{p}>0.01$.

Table 3: Pearson correlation between duration of diabetes and markers in SDM:

\begin{tabular}{|c|c|c|c|}
\hline & \multicolumn{2}{|c|}{ Duration } \\
\hline & $<\mathbf{1 0}$ years & 10-20 years & 20 years \\
\hline Lp(a) $\mathrm{mg} / \mathrm{dl}$ & $0.29 *$ & $0.5^{*}$ & $0.78^{* *}$ \\
\hline $\mathrm{CK}-\mathrm{mb}(\mathrm{ng} / \mathrm{ml})$ & 0.04 & 0.12 & $0.61^{* *}$ \\
\hline Troponin $(\mathrm{ng} / \mathrm{ml})$ & 0.08 & 0.19 & $0.71^{* *}$ \\
\hline (MDA) $\mathrm{nmol} / \mathrm{g}$ & 0.06 & 0.12 & $0.41 *$ \\
\hline MPO $(\mathrm{ng} / \mathrm{ml})$ & 0.06 & 0.10 & $0.32^{*}$ \\
\hline
\end{tabular}

*: significant $(\mathrm{p}<0.05) .{ }^{* *}$ : significant $(\mathrm{p}<0.01)$.

\section{Discussion}

In this study, cardiovascular markers were measured in Sudanese patients with type 2 diabetes. In which, lipids, apoA1 and B, lp(a), CK-MB, Troponin, MDA, and MPO were assessed and a major finding was increased of Apo B, lp(a), CK-MB, Troponin, and MDA in diabetic smoker than diabetic non-smokers. It's well documented that diabetes mellitus is commonly associated with cardiovascular abnormalities, similarly, smoking is correlated with the increase of the pathogenesis of many diseases such as atherosclerosis and cancers because it is a source of many toxins including free radicals and reactive oxygen species which they are playing a serious role in damaging tissues and increasing oxidative 

stress $^{29-31}$.

The combination of smoking and hyperglycemia can cause harmful consequences that may enhance vascular damage, there are various ways by which smoking elevated the risk of type 2 diabetes, among these, the chemicals in cigarettes cause bad effect on the human body and may interfere with tissues functions by increases of inflammation and reduces the effectiveness of insulin because of high inhaled levels of nicotine which lead to the severity of diabetes that may lead to heart, kidney, eye, and nerve complications ${ }^{32}$. In addition, strong evidence said that smoking can cause type diabetes ${ }^{33}$. Smoking can affect many surface molecules which help keep human cells in inflammatory conditions ${ }^{34}$, thus a lot of studies demonstrate the association between smoking and diabetes ${ }^{35-37}$.

It is widely known that smoking is substantially elevated the risk for both micro and macrovascular complications in type 2 diabetes because smoking released many radicals ${ }^{33}$ (38), this finding supporting to the present study in which $\operatorname{Lp}(\mathrm{a})$ and MDA were increased in SDM than in DM.

We recommend to the cessation of smoking to decreases the risk of cardiovascular and other abnormalities induced by smoking especially in diabetes and those with Familial hypercholesterolemia ${ }^{38}$, and overweight subjects.

In conclusion, smoking increased the risk of CVD in Sudanese type diabetes, the risk was increased with overweight, hypercholesterolemia and become serious in a long period of diabetes.

Conflict of interest:The author has nothing to declare.

Acknowledgement:My thank extend for the administrator and staff of Jabir Abu Aliz Diabetes Center (Khartoum, Sudan) for their help and support.

\section{References:}

1. Damaskos C, Garmpis N, Kollia P, et al. Assessing cardiovascular risk in patients with diabetes: An

update. Current cardiology reviews. 2019.

2. Ambrose JA, Barua RS. The pathophysiology of cigarette smoking and cardiovascular disease: an update. Journal of the American college of cardiology. 2004;43(10):1731-1737.

3. Roth GA, Mensah GA, Johnson CO, et al. Global burden of cardiovascular diseases and risk factors, 1990-2019: update from the GBD 2019 study. Journal of the American College of Cardiology. 2020;76(25):2982-3021.

4. Noor S, Bushara S, Sulaiman A, Elmadhoun WM, Ahmed M. Undiagnosed diabetes mellitus in rural communities in Sudan: prevalence and risk factors. 2015

5. Mohamed Ahmed A, Hassan Ahmed N. Diabetes mellitus in Sudan: the size of the problem and the possibilities of efficient care. Practical Diabetes International. 2001;18(9):324-327.

6. Osman HA, Elsadek N, Abdullah MA. Type 2 diabetes in Sudanese children and adolescents. Sudanese journal of paediatrics. 2013;13(2):17.

7. Ahmed AM. Evaluation of plasma leptin levels in Sudanese diabetic patients. Egyptian Academic Journal of Biological Sciences C, Physiology and Molecular Biology. 2012;4(1):107-112.

8. Elbagir MN, Eltom MA, Elmahadi EM, Kadam IM, Berne C. A population-based study of the prevalence of diabetes and impaired glucose tolerance in adults in northern Sudan. Diabetes care. 1996;19(10):1126-1128.

9. Ahmed AM, Elabid BEH, Abdalla MA. Association Between Lipoprotein (A) and Small Apo (A) Phenotypes and Coronary Heart Disease in Sudanese Diabetic Patients. Pakistan Journal of Medical Research. 2013;52(1).

10. Awadalla H, Noor SK, Elmadhoun WM, et al. Diabetes complications in Sudanese individuals with type 2 diabetes: overlooked problems in sub-Saharan Africa? Diabetes \& Metabolic Syndrome: Clinical Research \& Reviews. 2017;11:S1047-S1051.

11. Ahmed AM, Waggiallah HA, El-gari MM. Lipoprotein (a) level and other laboratory variables in diabetic patients. Egyptian Academic Journal of Biological Sciences C, Physiology and Molecular Biology. 2013;5(1):107-112.

12. Salih OA, AbdelAziz E. Underweight, overweight and obesity among Sudanese secondary school 
Medico-legal Update, October-December 2021, Vol.21, No. $4 \quad 79$

children of Khartoum State. The Ahfad Journal. 2007;24(1):59.

13. Ahmed AM. Correlation of Paraoxonase-1 with glycated hemoglobin and lipid profile among Sudanese diabetic patients. Pakistan journal of medical sciences. 2019;35(4):1050.

14. Ahmed AM, Khabour OF, Ahmed SM, Alebaid IA, Ibrahim AM. Frequency and severity of ketoacidosis at diagnosis among childhood type 1 diabetes in Khartoum state, Sudan. African Health Sciences. 2020;20(2):841-848.

15. Ahmed AM, Elabid BEH, Elhassan KEH, Waggiallah HA. Metabolic syndrome among undergraduate students attending medical clinics for obligatory medical screening. Tropical Journal of Pharmaceutical Research. 2015;14(2):317-321.

16. Ahmed AM, Khabour OF, Awadalla AH, Waggiallah HA. Serum trace elements in insulindependent and non-insulin-dependent diabetes: a comparative study. Diabetes, metabolic syndrome and obesity: targets and therapy. 2018;11:887.

17. Ahmed AM. Frequency Of Metabolic Syndrome Among Voluntary Screened Sudanese Healthy Subjects. Research Journal of Pharmaceutical, Biological and Chemical Sciences. 2019;10(2):563570 .

18. Ahmed Mohammed Ahmed AAR, Hussein Yousif Eledum. Relationship between Hypercholesterolemia, and Age, Gender and Body Mass Index. Research journal of pharmaceutical biological and chemical sciences. 2014;5(2):11371141.

19. Awadalla AH, Ahmed AM, Abdalla SB, Saleh AM, AlOmari AK. Serum?-Amylase Level in Sudanese Patients with Long Standing Diabetes Mellitus Type 2 in Khartoum State, Central Sudan. Medico Legal Update. 2020;20(4):31-34.

20. Ahmed AM, Al-Maghamsi M, Al-Harbi AM, Eid IM, Baghdadi HH, Habeb AM. Reduced frequency and severity of ketoacidosis at diagnosis of childhood type 1 diabetes in Northwest Saudi Arabia. Journal of Pediatric Endocrinology and Metabolism. 2016;29(3):259-264.

21. Ahmed AM, Ozbak HA, Hemeg HA. Effect of essential oil of traditional two Saudi mint types and its possible role in cardiovascular and throat health. International journal of clinical and experimental medicine. 2015;8(5):8060.
22. Rezk NL, Ahmed S, Iqbal M, Rezk OA, Ahmed AM. Comparative evaluation of caffeine content in Arabian coffee with other caffeine beverages. African Journal of Pharmacy and Pharmacology. 2018;12(2):19-26.

23. El Amin SET. School smoking policies and health science students' use of cigarettes, shisha, and dipping tombak in Sudan. Frontiers in public health. 2019;7:290.

24. Isomaa $\mathrm{B}$, Almgren $\mathrm{P}$, Tuomi $\mathrm{T}$, et al. Cardiovascular morbidity and mortality associated with the metabolic syndrome. Diabetes care. 2001;24(4):683-689.

25. Ahmed AM, Elabid BEH, Rhmtallah AA, Yousif $\mathrm{H}$, Eledum AH, Waggiallah HA. The Impact of hemodialysis and continuous peritoneal dialysis on lipoprotein (a) concentration and Apolipoprotein (a) Phenotypes in Patients with End Stage Renal Disease. Journal of American Science. 2014;10(8).

26. Elsukar AHAA, Ahmed AM. Assessment of Renal Functions among Saudi Arabian Pregnant Women in Jazan Region. Acta Medica. 2015;2:09.

27. Eweda SM, Rezk NL, Ahmed AM, Rezk OA. Effects of vanadium on oxidative stress and electrolytes balance of dyslipidemic male rats treated with simvastatin. African Journal of Pharmacy and Pharmacology. 2018;12(7):87-96.

28. Ahmed AM, Elhassan KEH, Abdallah HY, Elabid E, Almunawara-KSA A. Evaluation of myeloperoxidase in Saudi patients with Chronic renal failure. IJHSR. 2013;3(12):69-74.

29. Messner B, BernhardD. Smoking and cardiovascular disease: mechanisms of endothelial dysfunction and early atherogenesis. Arteriosclerosis, thrombosis, and vascular biology. 2014;34(3):509-515.

30. Ahmed AM. Salivary antioxidants superoxide dismutase and glutathione peroxidase in smokers comparing to non-smokers. 2013.

31. Waggiallah AMAH. Research Journal of Pharmaceutical, Biological and Chemical Sciences.

32. Health UDo, Services H. The health consequences of smoking - 50 years of progress: a report of the Surgeon General. In: Atlanta, GA: US Department of Health and Human Services, Centers for Disease ...; 2014.

33. Campagna D, Alamo A, Di Pino A, et al. Smoking and diabetes: dangerous liaisons and confusing relationships. Diabetology \& metabolic syndrome. 
2019;11(1):1-12.

34. Waggiallah $\mathrm{H}$, Baghdadi $\mathrm{H}$, Hemeg $\mathrm{H}$, et al. Phosphatidylserine induced up-regulation of Cluster Differentiation 36 and 47 on red cell membrane. Life Science Journal. 2014;11(6).

35. Saeed AA. Association of tobacco products use and diabetes mellitus-results of a national survey among adults in Saudi Arabia. Balkan medical journal. 2012;29(3):247.

36. Willi C, Bodenmann P, Ghali WA, Faris PD, Cornuz J. Active smoking and the risk of type 2 diabetes: a systematic review and meta-analysis. Jama. 2007;298(22):2654-2664.

37. Rimm EB, Chan J, Stampfer MJ, Colditz GA, Willett WC. Prospective study of cigarette smoking, alcohol use, and the risk of diabetes in men. Bmj. 1995;310(6979):555-559.

38. Ahmed SM, Ahmed AM, Albalawi AM, et al. A Homozygous Missense Variant in the APOB gene in Patients from Hypercholesterolemia Families. Egyptian Academic Journal of Biological Sciences C, Physiology and Molecular Biology. 2019;11(3):31-37. 